\title{
ESTADISTICAS SELECTAS
}

\section{LA POBLACION ACTIVA ESPANTOLA DE 1900 A 1957 (1)}

A Ño 1900

SECTORES ECONÓMLOS

VARONES MUYERES

TOTAL

Sector Agricola

1. Pesca y Caza .................. 47.463

47.463

2. Forestal y Agrícola

4.344 .867

4.344 .867

4.392 .330

4.392 .330

Sector Industrial

3. Minas y Canteras $\ldots \ldots \ldots \ldots$

81.064

591

$95.805 \quad 20.606$

$8.056 \quad 2.547$

5. Industrias Químicas... ... ... ...

22.418

603

7. Industrias Textiles

74.116

52,450

176.410

94.653

14.504

296

55.779

1.952

56.866

596

81.655

116.411

10.503

23.021

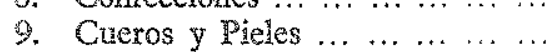

10. Industria de la Madera... ......

56.856

270.058

1.006

126.566

271.063

14.800

11. Metalurgia $\ldots \ldots \ldots c c c c c$

12. Trabajo de los Metales... .......

13. Construcción...................

27.902

718

57.731

57.462

14. Industrias restantes $\ldots \ldots \ldots \ldots$

882.978

176.018

271.064

28.620

1.058 .996

Sector Servicios

15. Transportes y Comunicaciones...

136.246

2.173

138.419

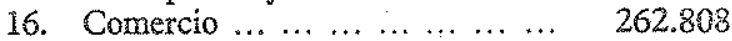

32.111

294.919

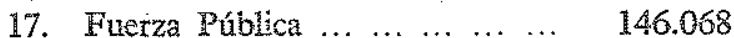

18. Administración Pública... ... ...

52.655

-

119.117

142

146.068

19. Profesiones liberales... .........

54.734

18.658

52.797

20. Culto y Clero

$\frac{36.510}{808.138} \quad \frac{264.942}{361.394} \quad \frac{301.452}{1.169 .532}$

43.368

137.775

21. Servicio Doméstico... ..........

(i) Los cuadros que aquí publicamos son un resumen de los contenidos en la excelente monografía que con el mismo título ha editado el Instivuso de Cultura Hispánica, Madrid 1957, y de la que dimos cuenta en la sección bibliográfica del anterior número de esta Revista. 
Sector Agricola

1. Pesca y Caza... ... ... .......... 56.792

56.792

2. Forestal y Agróna

4.623 .193

4.623 .193

4.679 .985

4.679 .985

Sector Inumbrat

3. Miruas, Canteras y Salinas ......

99.021

137

99.158

4. Industrias Alimenticias

96.611

15.882

112.493

5. Industrias Qúmicas... ... ... ...

9.513

2.222

11.735

6. Autes Grálicas

23.832

1.780

25.552

7. Industrias Textiles

82.329

51.630

133.959

8. Confecciones... ... ... ... ... ... 174.854

101.889

276.743

9. Cueros y Pieles

12.064

187

12.251

10. Industria de la Madera... ......

55.562

3.219

58.781

11. Metalurgia...

67.182

356

67.538

12. Trabajo de los Metales... ... ...

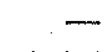

13. Construcción ...

282.599

823

283.422

14. Industrias restanes

39.752

383

40.135

943.319

178.448

1.121 .767

\section{Sector Servicios}

15. Transportes y Comunicaciones...

\begin{tabular}{rcr}
156.406 & 1.737 & 158.143 \\
307.900 & 25.962 & 333.862 \\
176.007 & - & 176.007 \\
41.066 & 143 & 41.209 \\
130.383 & 25.799 & 156.182 \\
55.770 & 46.762 & 102.532 \\
41.944 & 279.690 & 321.634 \\
\hline 909.476 & 380.093 & 1.289 .569
\end{tabular}

16. Comercio ... ... ............. 307.900

17. Fuerza Pública ... ... $\ldots . . . . . . \quad 176.007$

18. Aỏministración Pública... ... ...

19. Profesiones liberales... ... ... ...

20. Culto y Clero... .............

21. Servicio Doméstico ..........

$909.476 \quad 380.093 \quad 1.289 .569$ 
A กัก 1920

TOTAL

Sector Agricola

1. Pesca y Caza... ... ............. $\quad 69.824$

69.824

2. Forestal y Agrícola

4.232 .516

4.232 .516

4.302 .340

4.302 .340

Sector Industrial

3. Minas, Canteras y Salinas... ... 170.311

2.392

172.703

4. Industrias Alimenticias... ... ...

113.831

9.290

123.121

5. Industrias Químicas... $\ldots \ldots \ldots$

35.903

13.183

49.086

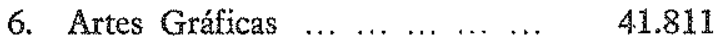

8.809

50.620

7. Industrias Textiles ... ... ... ... 109.644

134.007

243.651

8. Confecciones... ................. 136.843

93.195

9. Cueros y Pieles

25.644

2.573

230.038

10. Industria de la Madera... ... ...

153.929

2.128

28.217

11. Metalurgia... ... ... ......... 38.546

577

156.057

12. Trabajo de los Metales... ......

182.806

6.928

39.123

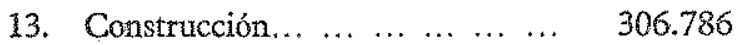

1.113

189.734

14. Industrias restantes.

55.934

2.951

307.899

1.371 .988

277.146

58.885

1.649 .134

Sector Servicios

15. Transportes y Comunicaciones...

217.846

1.679

219.525

16. Comercio

381.848 58.843 440.691

17. Fuerza Pública

230.954

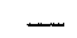

230.954

18. Administración Pública... ... ...

99.795

3.069

102.864

19. Profesiones liberales... . . . . . .

127.858

26.010

153.868

20. Culto y Clero.

57.570

52.090

109.660

21. Servicio Doméstico

34.280

272.916

307.196

1.150 .15

414.607

1.564 .758 
Sector Agricola

1. Pesca y Caza ... .............. 49.563

49.563

2. Forestal y Agrícola

3.776 .947

3.776 .947

3.826 .510

3.826 .510

Sector Industrial

3. Minas, Canteras y Salinas... ...

175.950

566

176.516

4. Industrias Alimenticias... ... ... 195.634

16.124

211.758

5. Industrias Químicas... ........

52.021

16.618

68.639

6. Artes Gráficas

38.007

822

38.829

7. Industrias Textiles $\ldots \ldots \ldots \ldots$

162.440

142.342

304.782

8. Confecciones ... ... ...........

65.721

111.561

177.282

9. Cueros y Pieles

158.033

10.398

168.431

10. Industria de la Miadera... ... ... 287.487

7.339

294.826

11. Metalurgia

54.472

158

289.829

6.068

54.630

12. Trabajo de los Netales

435.253

2.500

295.897

13. Construcción... $\ldots \ldots \ldots \ldots \ldots$

14. Industrias restantes... $\ldots . . . . . . \frac{-}{1.914 .847}$

314.496

437.753

2.229 .343

Sector Servicios

15. Transportes y Comunicaciones...

383.295

5.431

388.726

16. Comercio .

592.699

40.940

633.639

17. Fuerza Pública

298.461

16

298.477

18. Administración Pública... ... ...

108.571

3.019

111.590

19. Profesiones liberales... ... ... ... 311.018

43.155

354.173

20. Culto y Clero $\ldots \ldots \ldots \ldots \ldots \ldots$

71.103

65.078

136.181

21. Servicio Doméstico.

59.939

369.797

429.736

1.825 .086

527.436

2.352 .522 
A ก̃ $O 1940$

Sector Agrícola

1. Pesca y Caza

83.102

83.102

2. Forestal y Agrícola

4.441 .920

4.441 .920

4.525 .022

4.525 .022

Sector Industrial

3. Minas, Canteras y Salinas ... ...

122.882

529

123.411

4. Industrias Alimenticias... ... ... 171.257

14.359

185.616

5. Industrias Químicas...

45.253

18.655

63.908

6. Artes Gráficas $\ldots \ldots \ldots \ldots \ldots$

38.774

2.901

41.675

7. Industrias Textiles

105.830

147.352

253.182

8. Confeccione

47.963

88.110

136.073

9. Cueros y Pieles

121.374

14.763

136.137

10. Industrias de la Madera... ... ... 223.502

3.249

226.751

11. Metalurgia...

42.046

358

12. Trabajo de los Metales... ... ... 306.933

4.135

42.404

13. Construcción

460.856

1.830

311.068

14. Industrias restantes

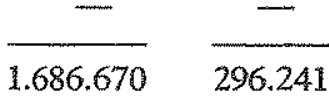

462.686

$1.686 .670 \quad 296.241$

1.982 .911

Sector Servicios

15. Transportes y Comunicaciones...

343.738

6.336

350.074

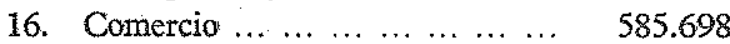

72.963

658.661

17. Fuerza Pública

430.236

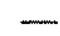

430.236

18. Administración Pública... ... ...

95.794

5.646

101.440

19. Profesiones liberales... ... . . . . 374.754

69.932

417.686

20. Culto y Clero... ... ..........

46.439

61.170

107.609

21. Servicio Doméstico

41.784

342.184

383.968

1.891 .443

558.231

2.449 .674 
Sector Agricola

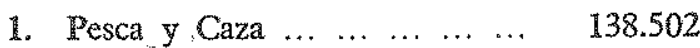

138.502

2. Forestal y Agricola ... ... ... 4.797 .137 4.797 .137

4.935 .639

4.935 .639

Sector Industrial

3. Minas, Canteras y Salinas ...

\begin{tabular}{rrr}
176.994 & 2.365 & 179.359 \\
212.385 & 30.500 & 242.885 \\
104.777 & 24.623 & 129.400 \\
45.268 & 7.550 & 52.818 \\
130.415 & 179.830 & 310.245 \\
42.206 & 106.673 & 148.879 \\
121.785 & 24.768 & 146.553 \\
221.822 & 5.980 & 227.802 \\
101.337 & 4.906 & 106.243 \\
415.091 & 17.610 & 432.701 \\
678.218 & 11.051 & 689.269 \\
72.050 & 15.958 & 88.008 \\
\hline 2.322 .348 & 431.814 & 2.754 .162
\end{tabular}

5. Industrias Químicas $\ldots \ldots \ldots$

6. Artes Gráficas .............

7. Industrias Textiles $\ldots . \ldots$.

8. Confecciones $\ldots . \ldots \ldots \ldots \ldots$

9. Cueros y Pieles $\ldots \ldots \ldots \ldots$

10. Industria de la Madera .......

11. Metalurgia $\ldots \ldots \ldots \ldots \ldots$

12. Trabajo de los Metales ... ...

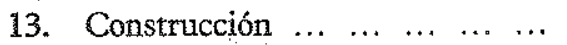

14. Industrias restantes $\ldots \ldots \ldots$

$2.322 .348 \quad 431.814$

2.754 .162

\section{Sector Servicios}

15. Transportes y Comunicaciones. $406.545 \quad 18.421 \quad 424.966$

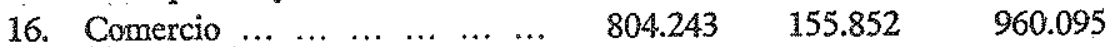

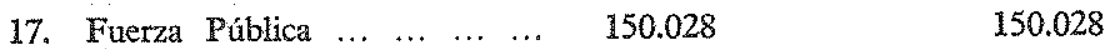

18. Administración Pública ... ...

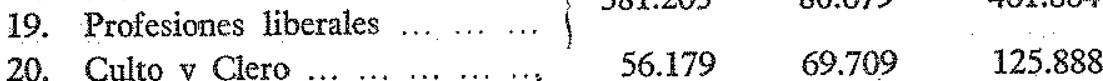

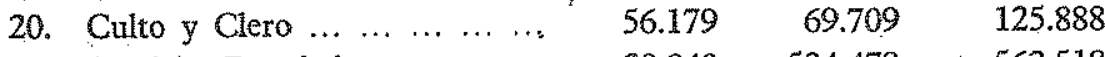

21. Servicio Doméstico $\ldots \begin{array}{llllll} & \ldots & \ldots & 28.040 & 534.478 & 562.518\end{array}$

$\begin{array}{lll}1.826 .240 & 859.139 & 2.685 .379\end{array}$ 


\section{A}

TOTAL

Secior Agricola

1. Pesca y Caza

4.783 .339

4.783 .339

2. Forestal y Agrícola

\section{Sector Industrial}

3. Minas, Canteras y Salinas....... 210.170

4.003

214.173

4. Industrias Alimenticias

(En la cifra que a continuación

5. Industrias Químicas $\ldots \ldots \ldots$ se pone, quedan incluidas todas

6. Artes Gráficas las rúbricas no especificadas del

7. Industrias Textiles sector industrial.)

8. Confecciones $1.833 .146 \quad 511.746$

2.344 .892

9. Cueros y Pieles (1)

10. Industria de la Madera

11. Metalurgia

12. Trabajo de los Metales $\ldots . . .$.

13. Construcción $\ldots \begin{array}{llllll} & \ldots & \ldots & \ldots & \ldots & 702.233\end{array}$

14. Industrias restantes (Electric.)...

\begin{tabular}{|c|c|c|}
\hline 702.233 & 5.004 & 707.237 \\
\hline 67.38 & 2.335 & 69.723 \\
\hline & & 3.336 .0 \\
\hline
\end{tabular}

Sector Servicios

15. Transportes y Comunicaciones . $482.593 \quad 22.483 \quad 505.076$

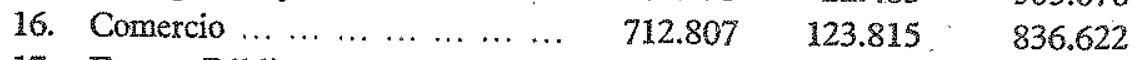

17. Fuerza Pública

18. Administración Pública $\ldots \ldots$...

19. Profesiones liberales $\ldots . \ldots$.

20. Culto y Clero $\ldots \ldots \ldots \ldots, \ldots$

$958.220 \quad 866.704 \quad 1.824 .924$

21. Servicio Doméstico 
